\title{
The Study of Multiradius Roller Running Process
}

\author{
Andrey Krechetov $^{l}$ and Kristina Mitrofanova ${ }^{1}$ \\ ${ }^{1}$ T.F. Gorbachev Kuzbass State Technical University, Department of mechanical engineering \\ technology, 650000 Kemerovo, 28 Vesennya st., the Russian Federation
}

\begin{abstract}
The results of theoretical and experimental studies of the surface of the sample of steel 45 after surface plastic deformation (SPD) with multi-radius roller (MR-roller) is shown. The goal of this study is to expand the technological capabilities of the method of SPD through the use of a new design of the deforming tool developed at the Department of Engineering Technology of KuzSTU. The advantage of the MR-roller (Patent RU № 2557377) over the traditional tool for SPD (single-radius roller) is the possibility of creating a large hydrostatic pressure in the deformation zone, without destroying the surface layer of the processed material. The research technique included finite element modeling (FEM), microhardness measurement, metallographic studies of the sample structure. As a result of the study, some regularities of the process of hardening by a multi-radius tool with high hydrostatic pressure and a large number of quasi-monotonic deformation sites were revealed. The results indicate a significant hardening without metal destruction and the formation of nanoscale grains, which allows to improve the properties of rolled products in the application of high operating loads.
\end{abstract}

\section{Introduction}

It is known that a number of technological requirements are imposed on the quality of the material of the surface layer of critical machine parts, including: corrosion resistance, wear resistance, the ability to tolerate intense deformation without destroying the surface layer, etc. Therefore, today there is a need to improve the methods of finishing.

One of the most effective methods of finishing is surface plastic deformation.

The field of surface plastic deformation is relevant to such areas as the intensification of the stress-strain state with the aim of achieving high average normal stress (hydrostatic pressure), detection mechanisms and the establishment of regularities of plastic deformation, complicating the geometry of the deforming tools, etc.

At present, a number of studies have proved the possibility of obtaining nanostructures in surface layer by surface plastic deformation.

Thus, Prof. Markus L. I. was one of the first to discover the effect of nanostructuring of the material in the process of studying the effect of diamond smoothing (burnishing process) on the quality of the surface layer and the performance properties of the bearing raceways made of their steel SHX-15 (100Cr6) [1]. The practical implementation of the study led to the creation of advanced technology of finishing of bearing parts with high 
reliability. Optimal modes of burnishing process during hardening of steel rings SHX-15 $(100 \mathrm{Cr} 6)$ can be assigned to the thin crystal structure of the metal.

The scientific groups [2] believe that the surface plastic deformation process is an effective method of preparing austenitic stainless steel surfaces for subsequent nitriding. In the present study, after rolling the ball, the authors found an increase in the density of the crystal lattice and the presence of a fine structure in the surface layer. The data obtained correlated with the results of Altenberger I. [3-4].

Abdolreza J.T estimated the effect of tungsten ball rolling $(\varnothing 20 \mathrm{~mm})$ on the microstructure of the surface layer of stainless steel AISI 316L [5]. X-ray analysis and transmission electron microscopy revealed the presence of ultrafine and nanoscale equiaxial grains with an average size of $200 \mathrm{Nm}$ and $70 \mathrm{Nm}$ and random orientations. In addition, structural changes were observed in the form of microhardness increase from $200 \mathrm{HV}$ to $450 \mathrm{HV}$ and deformation martensitic transformation. These effects increased with the number of moves of the instrument. Similar effects were obtained in [6-16].

In [14] the subtle physical methods of researches it is established some regularities occurring in the surface layer in the processing of surface plastic deformation tungsten ball $(\varnothing 6 \mathrm{~mm})$ and the mechanism of hardening. The presence of large values of residual stresses (866-1315 MPa) the authors associated with the formation of metal ahead of the roller instrument atomic rearrangement of the metal particles through the mechanism of "clutter". A similar mechanism of strengthening is considered in the work [15]. As noted by the authors, the increase in the total width of the half-highs (FWHM) is associated with an increase in the density of the dislocation grid and the localization of large values of plastic deformation. When processing with a pressure of $50 \mathrm{MPa}$, the percentage of grains with small-angle boundaries increases to $96 \%$ (depth of $50 \mu \mathrm{m}$ ). The formation of small-angle grain boundaries $\left(1^{\circ}<\theta^{\prime \prime} \leq 15^{\circ}\right)$ makes it difficult to slip between the grains and as a result leads to the hardening of the material, which is confirmed by the study of Valiev R. Z. [16].

The Department of mechanical engineering of Kuzbass state technical University developed the new design of the deforming tools, having a dedicated work profile. One of which is a multiradius roller (MR-roller) (Patent RU № 2557377) (Fig. 1) [17].

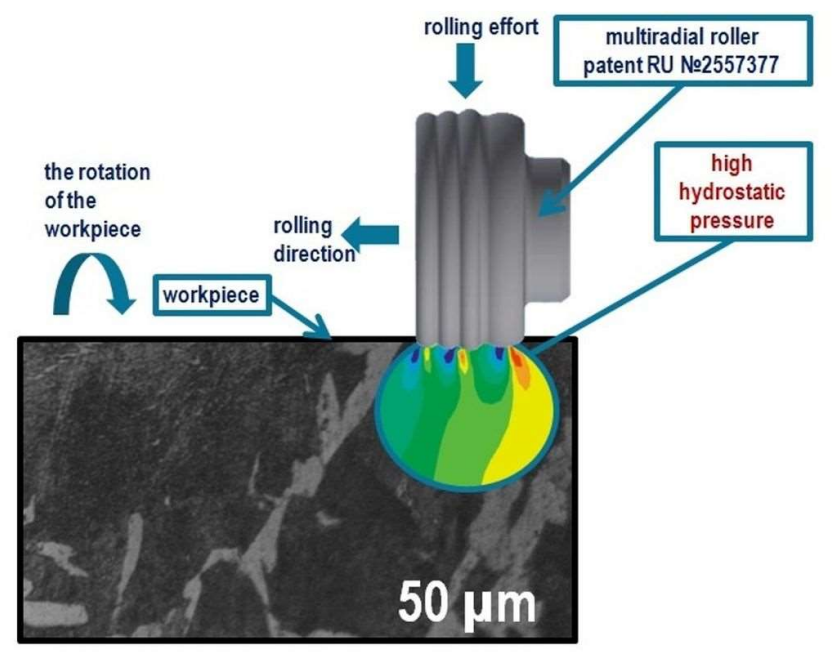

Fig.1. Scheme of interaction of MR-roller with the workpiece

A small study of the process required theoretical and experimental studies, including: finite element modeling of the process, machine experiment on rolling the MR- roller; study of the structure and durometric properties of the samples. 
The purpose of the work is to expand the technological capabilities of the surface plastic deformation process through the use of an MR-roller, which creates more hydrostatic pressure in the deformation zone.

\section{Researches}

On the basis of the works devoted to the account of technological inheritance (TN) in the processes of cutting, surface plastic deformation and operational fatigue loading, [18-20] finite element modeling (FEM) of the stress-strain state of the surface layer of metal after processing by the MRroller is carried out. Modeling and analysis of the problem in Ansys took place in several stages. The first stage included the construction of a geometric model of the workpiece and the tool. On the surface rigidly mounted on the lower and lateral boundary of the cylindrical part $(80 \times 60 \mathrm{~mm})$, with properties given in table 1 , the effect multimediyny the roller and profile radii: $R_{p r l}=1 \mathrm{~mm}$ with interference $h_{d 1}=0.05 \mathrm{~mm} ; R_{p r 2}=1 \mathrm{~mm}$ with interference $h_{d 2}=0.10 \mathrm{~mm} ; R_{p r 3}=1 \mathrm{~mm}$ with interference $\mathrm{h}_{\mathrm{d} 3}=0.15 \mathrm{~mm} ; \mathrm{R}_{\mathrm{pr} 4}=3 \mathrm{~mm}$ with interference, $\mathrm{h}_{\mathrm{d} 4}=0.05 \mathrm{~mm}$. At the second stage was carried out the solution of the problem consisting of 340 steps. Initially, the indenter is from the surface with a gap of $0.3 \mathrm{~mm}$ in order to "not touch" the plastic wave. The surface of the workpiece does not have a plastic zone - the center of deformation. All movements are made from the original position in the XYZ coordinate system. Each step was carried out in several moves: 1 move - the displacement of the indenter down the Y-axis at $0.32 \mathrm{~mm}$ (creating the introduction with the preload $0.02 \mathrm{~mm}$ ); 2 stroke displacement of the indenter left on the $\mathrm{X} 0.1 \mathrm{~mm}$ (to be carried out the removal of the indenter and the displacement at feed $0.1 \mathrm{~mm}) ; 3$. the stroke - displacement of the indenter down the Y-axis at $0.32 \mathrm{~mm}$ (creating the introduction, i.e. preload $0.02 \mathrm{~mm}$ ); 4 - stroke-displacement of the indenter to the left on $\mathrm{X}$ by $0.2 \mathrm{~mm}$ (is the withdrawal of the indenter and the displacement on the feed $-0.1 \mathrm{~mm}$ ). At the third stage postprocessing was performed.

The simulated metal was considered isotropic with parameters corresponding to the mechanical parameters of steel 45 (GOST 1050-88 or 1045 ASTM) in the delivery state. Due to the low heating in the processing of surface plastic deformation, the resulting deformations were only of a mechanical nature. The used bilinear approximation of the flow curve took into account the hardening of the metal (table. 1).

Table 1. Physical and mechanical properties of metal and flow curve parameters (steel 45, GOST 105088 or 1045 ASTM)

\begin{tabular}{|l|c|c|}
\hline Young's modulus & $E, \mathrm{MPa}$ & $2 \times 10^{11}$ \\
\hline Density & $\rho, \mathrm{kg} / \mathrm{m}^{3}$ & 7800 \\
\hline Poisson ratio & $v$ & 0.3 \\
\hline Friction coefficient & $\eta$ & 0.21 \\
\hline Extrapolated yield strength & $\sigma_{e t}, \mathrm{MPa}$ & $3.66 \times 10^{8}$ \\
\hline Tangential module & $T_{\text {mod }}, \mathrm{MPa}$ & $2.596 \times 10^{6}$ \\
\hline
\end{tabular}

After solving the problem, the following values were fixed in the selected section for each modeling step: the coordinates of the nodes that make up the displacement vector of the nodes, the components of the stress tensor, the components of the elastic, plastic and total elastic-plastic deformation tensor.

Experimental studies were in the manufacture of annular samples $\emptyset 60 \mathrm{~mm}$ of annealed steel 45 one delivery and rolling the MR-roller modes presented in table 2.

The hardness of the steel was $190 \mathrm{HV}$. Machining included roughing and finishing turning with small allowances of 0.25 and $0.15 \mathrm{~mm}$, respectively, feed $0.07 \mathrm{~mm} / \mathrm{Rev}$ and spindle speed of $1600 \mathrm{Rev} / \mathrm{min}$. After that, the preliminary and final grinding with sandpaper with low grit was carried out. This treatment allowed to exclude the influence of 
roughness and defective layer of the workpiece on the quality of the machined surface of the part.

Table 2. State of samples and modes of SPD

\begin{tabular}{|c|c|c|c|}
\hline sample no., condition & $\begin{array}{l}\text { Running-in } \\
\text { force, } P, \mathrm{H}\end{array}$ & $\begin{array}{l}\text { Traverse feeding, } \\
S, \mathrm{~mm} / \mathrm{rpm}\end{array}$ & $\begin{array}{l}\text { Speed, } \\
n, \mathrm{rpm} / \mathrm{min}\end{array}$ \\
\hline $\begin{array}{l}\text { Model No. 1, initial state } \\
\text { (electropolishing) }\end{array}$ & \multicolumn{3}{|c|}{-} \\
\hline $\begin{array}{l}\text { Sample No. 2, MR-roller the treatment } \\
\text { mode } 1\end{array}$ & 2000 & \multirow[t]{2}{*}{0.07} & \multirow{2}{*}{630} \\
\hline $\begin{array}{l}\text { Sample No. 3, MR-roller the treatment } \\
\text { mode } 2\end{array}$ & 2500 & & \\
\hline
\end{tabular}

Treatment of SPD MR-roller $\emptyset 60 \mathrm{~mm}$ were performed on screw-cutting machine using a special roller set in two modes, differing by the force of the orbital.

Measurement of microhardness was carried out on the device DuraScan-20 vertically from the surface in 11 sections, each of which was applied to 30 prints with loading HV $0.980665 \mathrm{~N}$. The study of the microstructure of the material was carried out on an optical microscope Altami MET1MT, which allows to increase the image of the structure more than 1000 times.

\section{Results and discussion}

For fig. 2 shows the distributions of the component of the stress tensor after 339 and 340 of the step.

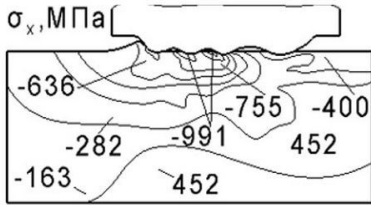

a)

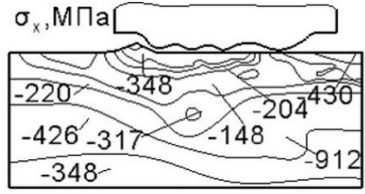

d)

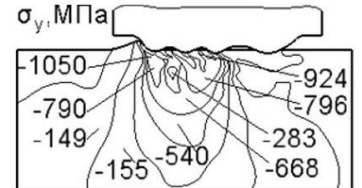

b)

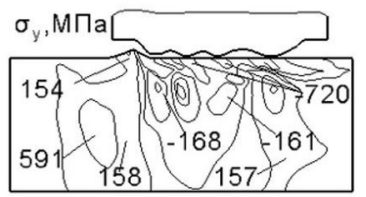

e)

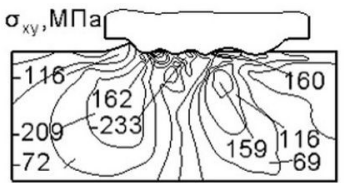

c)

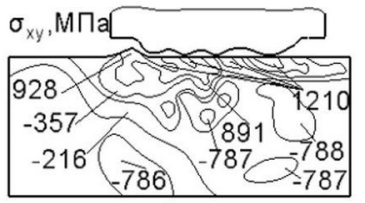

f)

Fig. 2. The distribution component of the stress tensor $\left(\sigma_{x}, \sigma_{y}, \sigma_{x y}\right)$ after 339 (a-c) and 340 (d-f) the steps of modeling

Axial component $\sigma_{\mathrm{x}}$ after 339,340 steps varies from -991 to $+452 \mathrm{MPa}$. The highest values of compressive stresses $(-636 \ldots-755 \mathrm{MPa})$ can be observed at the 339 load step mainly in front of small deforming elements $\left(\mathrm{R}_{\mathrm{pr} 1}, \mathrm{R}_{\mathrm{pr} 2}, \mathrm{R}_{\mathrm{pr} 3}\right)$. At step 340 unloading compressive stresses reach values $(-220 . .-348 \mathrm{MPa})$. The radial component $\sigma \mathrm{y}$ is characterized by high values $(-790 \ldots-1050 \mathrm{MPa})$ of compressive stresses at step 339 (load), in the region of formation of a plastic wave of the metal ahead of the deforming element $\left(R_{p r 1)}\right.$. At 340 step (unloading) values $\sigma_{\mathrm{y}}$ range from -160 to $-720 \mathrm{MPa}$ predominantly under small deforming element $\left(R_{\mathrm{pr} 1}, \mathrm{R}_{\mathrm{pr} 2}, \mathrm{R}_{\mathrm{pr} 3}\right)$. The tangential component $\sigma_{\mathrm{xy}}$ at the loading stage it reaches negative values (-116...-233 MPa) mainly in the anterior zone of the deformation site. In the posterior zone of the deformation focus, positive values prevail $(116 \ldots 160 \mathrm{MPa})$. As an 
example (table. 3 ) the parameters of the roughness of steel 40 , after treatment with an MRroller, in similar modes.

Table 3. Roughness parameter.

\begin{tabular}{|l|c|c|c|c|}
\hline \multirow{2}{*}{$\begin{array}{l}\text { Sample no., } \\
\text { condition }\end{array}$} & \multicolumn{4}{|c|}{ Roughness parameter } \\
\cline { 2 - 5 } & $\begin{array}{c}\text { Arithmetic mean } \\
\text { deviation of the } \\
\text { profile, } \\
\text { Ra, } \mu \mathrm{m}\end{array}$ & $\begin{array}{c}\text { Root mean } \\
\text { square } \\
\text { roughness, } \mathrm{R}_{\mathrm{q}}, \\
\mu \mathrm{m}\end{array}$ & $\begin{array}{c}\text { The maximum } \\
\text { height of the } \\
\text { profile, } \mathrm{R}_{\text {max }}, \\
\mu \mathrm{m}\end{array}$ & $\begin{array}{c}\text { The average } \\
\text { pitch of the } \\
\text { irregularities, } \\
\text { Sm, } \mu \mathrm{m}\end{array}$ \\
\hline $\begin{array}{l}\text { Model No. 1, } \\
\text { initial state } \\
\text { (electropolishin } \\
\text { g) }\end{array}$ & 0.826 & 1.062 & 5.648 & 122.2 \\
\hline $\begin{array}{l}\text { Sample No. 2, } \\
\text { MR-roller the } \\
\text { treatment } \\
\text { mode 1 }\end{array}$ & 0.288 & 0.403 & 2.321 & 112.4 \\
\hline $\begin{array}{l}\text { Sample No. 3, } \\
\text { MR-roller the } \\
\text { treatment mode } \\
2\end{array}$ & 0.260 & 0.378 & 2.759 & 111.6 \\
\hline
\end{tabular}

For fig. 3 the scheme of microhardness measurement is presented. It was found that in comparison with the initial state after treatment with an MR-roller, an increase in microhardness is observed not only in a thin surface layer (depth $50 \mu \mathrm{m}$ ), but also at a depth of $1710 \mu \mathrm{m}$ (Fig.4).

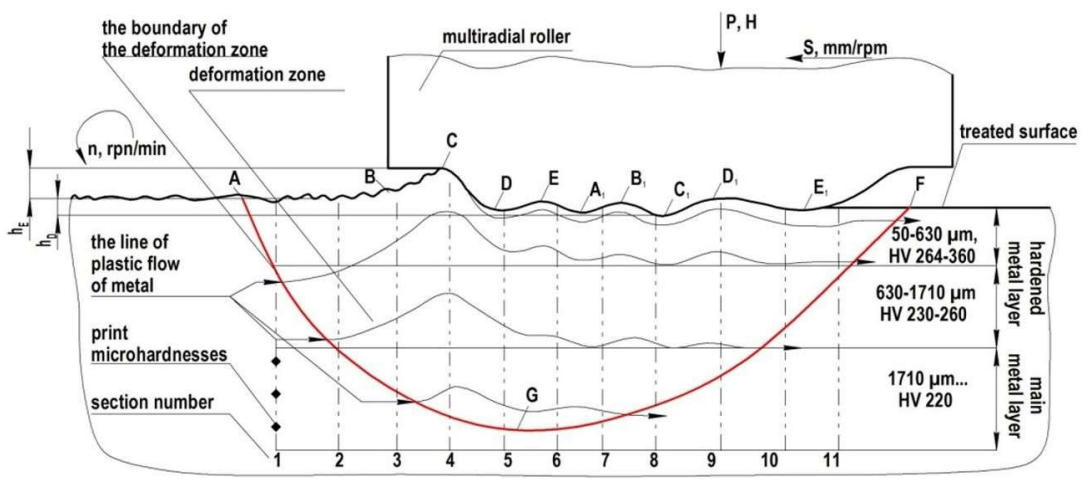

Fig. 3. The scheme of measurement of microhardness

In the area of plastic waves are characterized by a high microhardness: HV 264-360 at a depth of 50-630 $\mu \mathrm{m}$ and the average values of the microhardness on the border of the deformation 230-260 $\mathrm{HV}$ at a depth of 630-900 microns. At the boundary of the deformation site at a depth of 900-1350 microns, microhardness values of 246-255HV are observed. Also characterized by high microhardness values of $270-280 \mathrm{HV}$ at a shallow depth of 50-540 microns. In the contact area of the treated surface with the first deforming element of the roller $\mathrm{R}_{\mathrm{pr} 1}=1 \mathrm{~mm}$ the high values of the microhardness $\mathrm{HV}$ on the small 253290 the depths of 50-270 $\mu \mathrm{m}$, and low values of the microhardness on the border of the deformation 200-224 HV at a depth of $1170 \mu \mathrm{m}$. 


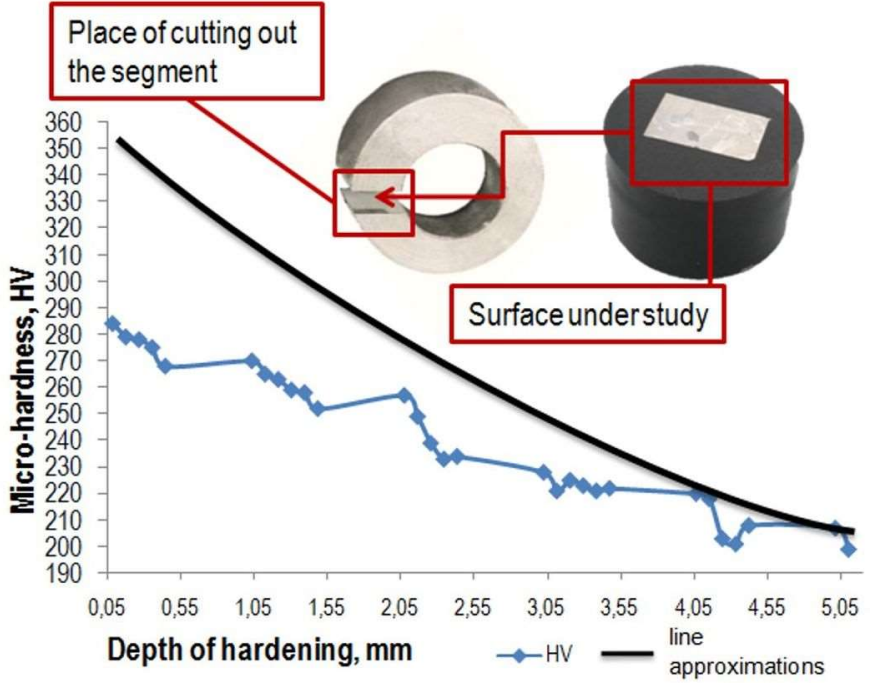

Fig.4. Schedule changes of microhardness in the cross section 1

Contact zone of the treated surface with the second and third indenter $\mathrm{R}_{\mathrm{pr} 2}=1 \mathrm{~mm}$ and $\mathrm{R}_{\mathrm{pr} 3}=1 \mathrm{~mm}$ it is characterized by high values of microhardness, especially at the top of the plastic wave 269-314 HV. Contact area of the fourth roller radius $R_{p r 4}=3 \mathrm{~mm}$ it is characterized by average values of microhardness $234-250 \mathrm{HV}$.

For fig. 5 the microstructure of the studied samples in the initial state and after treatment with an MR-roller in mode 1 is presented.

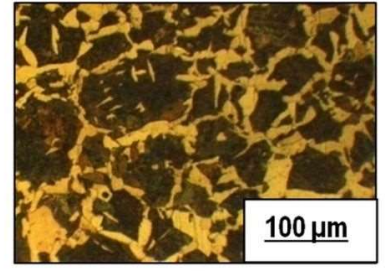

a)

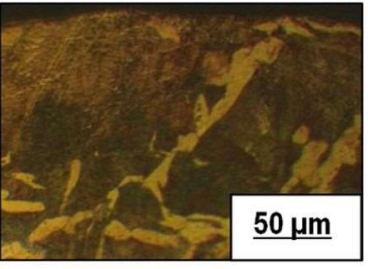

b)

Fig. 5. Microstructure of steel 45: a) initial state (annealing + electropolishing); b) SPD using MRroller mode 1

After a preliminary study of the steel structure, it was found that in the initial state the annealed steel has a ferrite-pearlite structure (Fig. 5, a). The result of the SPD MR-roller in the surface layer registers the elongation of pearlitic lamellae in the direction of the plastic flow of metal (Fig. 5, b). The results obtained confirmed the presence of nanoscale grains in a thin surface layer.

\section{Conclusion}

The effect of SPD using a multi-radius roller on the structural state and microhardness of the surface layer of annealed steel 45 is studied. It was found that the treatment of the MRroller leads to significant structural changes, including an increase in microhardness to 360 $\mathrm{HV}$ and a decrease in roughness. Some regularities of the process of hardening by a multiradius tool with high hydrostatic pressure and a large number of sites of quasi-monotonic deformation are revealed. The results indicate a significant hardening without metal 
destruction and the formation of nanoscale grains, which allows to improve the properties of rolled products in the application of high operating loads.

\section{References}

1. L. I. Marcus, V. M. Smelyanskiy, Diamond smoothing (Research Institute-Auto Industry, Moscow, 1971)

2. T. A. Jafari, S. R., Hosseini, S. M., Naderi, Int. Nano. Lett., 7 (2017)

3. I. Altenberger, B. Scholtes, U. Martin, H. Oettel, Mater. Sci. Eng., 264 (1999)

4. I. Nikitin, I. Altenberger, Mater. Sci. Eng., 465 (2007)

5. J.T. Abdolreza, Mater. Sci. \& Eng. Int. Jour., 1, 3 (2017)

6. R.K. Nalla, I. Altenberger, U. Noster, G.Y. Liu, B. Scholtes, R.O. Ritchie, Mater. Sci. Eng. A, 355, 1 (2003)

7. V.P. Kuznetsov, A.V. Makarov, N.A. Pozdeeva, R.A. Savrai, A.S. Yurovskikh, I.Yu. Malygina, A.E. Kiryakov, Uproch. Techn. Pokr., 9 (2011)

8. V.P. Kuznetsov, Naykoyom.Techn. Mashinost., 11 (2013)

9. B. Nagarajan, D. Kumar, Z. Fan, S. Castagne, Mater. Sci. Eng., 728 (2018)

10. J. Caudill, J. Schoop, I. S. Jawahir, Adv. Mater. and Proc. Techn. (2018)

11. S. R. Kondavalasa, P. Aditya, J. Rohit, S. Shanmugam, I. Samajdarb, K. V. Vijay, W. Gerhard, Mater. Character., 153 (2019)

12. Z.M. Wang, Y.F. Jia, X.C. Zhang, Y. Fu, C.C. Zhang, S.T. Tu, Critic. Rev. in Sol. Stat. and Mater. Sci., (2019)

13. Q. Wang, J. Ren, Y. Wang, C. Xin, L. Xiao, D. Yang, Mater. Sci. Eng: A., 754 (2019)

14. D. Kumar, S. Idapalapati, W. Wang, A. Bhowmik, Mater. Sci. Eng: A (2019)

15. V.M. Pascale Balland, T. Laurent, D. Fabien, Precis. Eng., 37 (2013)

16. R.Z. Valiev, Nat. Mater., 3, (2004)

17. V. Yu Blumenstein, A. A. Krechetov, M. S. Makhalov, O. A. Ostanin, Patent RU 2557377, Byul., 27:2 (2016)

18. V. Yu Blumenstein, Kh. M. Rakhimyanov, M. R. Heifetz, A. A. Kleptzov, AIP Conf. Proc., 1698 (2016)

19. M. S. Mahalov, V. Yu. Blumenstein, IOP Conf. Ser. Mater. Sci. and Eng., 126 (2016)

20. M. S. Mahalov, V. Yu. Blumenstein, IOP Conf. Ser. Mater. Sci. and Eng., 253, 1 (2017) 